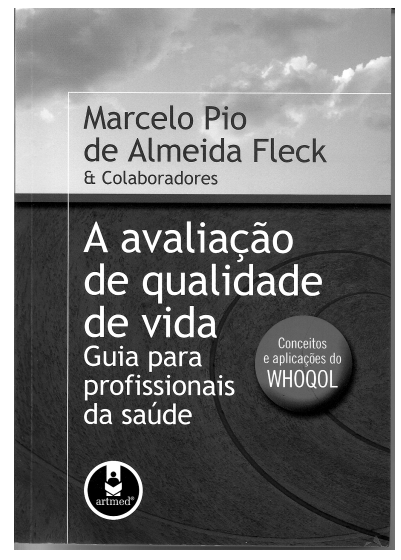

\section{A avaliação de qualidade de vida: guia para profissionais da saúde}

Marcelo Pio de Almeida Fleck (org.)

Porto Alegre, Artmed, 2008

\begin{abstract}
José Carlos Rosa Pires de Souza ${ }^{1}$, Neomar Herculano de Souza Barros ${ }^{2}$
${ }^{1}$ Psiquiatra. Doutor em Saúde Mental, Universidade Campinas (UNICAMP), Campinas, SP. PhD, Faculdade Medicina de Lisboa, Lisboa, Portugal. Professor, Universidade Católica Dom Bosco (UCDB), Campo Grande, MS. ${ }^{2}$ Psicóloga. Especialista em Terapia Cognitivo-Comportamental e Mestre em Psicologia, UCDB. Professora, UCDB. Psicóloga clínica, Hospital Psiquiátrico Nosso Lar, Campo Grande, MS.
\end{abstract}

Dr. Marcelo Pio de Almeida Fleck - psiquiatra, professor adjunto do Departamento de Psiquiatria e Medicina Legal da Universidade Federal do Rio Grande do Sul (UFRGS), Coordenador do Grupo WHOQOL no Brasil - nos presenteia com este tomo de extrema relevância para os estudos e pesquisas sobre a avaliação da qualidade de vida (QV), especialmente em relação aos conceitos e aplicações do questionário WHOQOL (World Health Organization Quality of Life), elaborado, criteriosamente, pela Organização Mundial de Saúde (OMS). O livro possui 228 páginas, muito bem distribuídas em 20 capítulos, assinados por 25 eméritos pesquisadores da área de QV. O mesmo destina-se a estudantes, profissionais e pesquisadores da área da saúde e afins. Sua linguagem é clara e objetiva, facilitando a compreensão de seu conteúdo até mesmo pelos iniciantes no assunto da QV. Realmente os autores alcançaram, com esta obra, os seus objetivos de torná-la um "guia para profissionais da saúde". O livro está dividido em duas partes. A primeira com nove capítulos e a segunda com 11, sendo, inicialmente, tratado o conceito de QV e o Projeto WHOQOL; já na segunda parte, são apresentadas algumas aplicações do questionário WHOQOL em amostras clínicas e não-clínicas.
No capítulo 1, o professor Marcelo Fleck faz, inicialmente, uma abordagem retrospectiva desde os estudos de base epidemiológica sobre a felicidade e o bem-estar até os modelos teóricos e conceituais atuais de QV. O autor é enfático e correto ao afirmar que "a definição proposta pela OMS é a que melhor traduz a abrangência do construto qualidade de vida. O Grupo WHOQOL definiu qualidade de vida como a percepção do indivíduo de sua posição na vida, no contexto de sua cultura e no sistema de valores em que vive em relação a suas expectativas, seus padrões e suas preocupações". Ainda acrescenta o autor que três aspectos são fundamentais sobre este construto: subjetividade, multidimensionalidade e dimensões positivas e negativas.

No capítulo 2, o psiquiatra Donald L. Patrick, professor da Universidade de Seattle, EUA, discute se a qualidade de vida pode ser medida e como. Argumenta as razões para se medir a QV e a questão da individualização das avaliações, assim como as suas propriedades psicométricas. Este tem sido um assunto muito discutido nas pesquisas dos programas de pós-graduação das universidades brasileiras que abrangem a área da $\mathrm{QV}$.

No terceiro capítulo, o psiquiatra Somnath Chatterji e Jerome Bickenbach, professor e detentor do Queen's 
Research Chairdo Departamento de Filosofia e Faculdade de Direito e Medicina da Queen's University, iniciam o seu texto até mesmo com referências bíblicas, relacionando com os estudos sobre a QV. Apresentam uma estrutura conceitual para a experiência da saúde e a mensuração do seu componente objetivo, assim como do bem-estar.

No capítulo seguinte, Mick Power, professor de Psicologia Clínica e consultor de pesquisa da OMS no Projeto WHOQOL, apresenta uma visão geral do que vem a ser o Projeto WHOQOL da OMS, desde o desenvolvimento do questionário WHOQOL original à sua versão breve, seus domínios e devidas facetas.

O professor Marcelo Fleck e o psiquiatra Eduardo Chachamovich discutem, detalhadamente, no quinto capítulo, como foi o desenvolvimento do questionário WHOQOL-100, dentro do modelo teórico da OMS, até a sua versão em português. Encerram disponibilizando este instrumento no site da Universidade Federal do Rio Grande do Sul (www.ufrgs.br/psiq), com a sua sintaxe de análise em linguagem SPSS (Statistical Package of the Social Sciences). Este site é referência obrigatória para os estudiosos da QV.

No sexto capítulo, os mesmos autores do anterior abordam o desenvolvimento da versão abreviada do WHOQOL (WHOQOL-bref), a original e sua versão em português. Alertam que os cuidados básicos a serem atendidos na aplicação do WHOQOL-bref são semelhantes aos observados em relação ao WHOQOL-100.

No capítulo 7, o professor Marcelo Fleck e o psiquiatra Rogério Zimpel apresentam o desenvolvimento, a aplicação e a validação do WHOQOL-HIV, que se trata de um "instrumento genérico modificado, capaz de conciliar a necessidade de generalização e comparação com outros estudos e que, ao mesmo tempo, fosse específico o suficiente para essa situação".

No oitavo capítulo, o professor Fleck, a psiquiatra Neusa Sicada Rocha, a psicóloga Raquel Gehrke Panzini e a médica Joana Silveira Pargendler apresentam o desenvolvimento do módulo para avaliar espiritualidade, religiosidade e crenças pessoais do WHOQOL (WHOQOL-SRPB). Até pouco tempo atrás, ciência, espiritualidade e religiosidade não eram discutidas tão conjuntamente; contudo, com o desenvolvimento do WHOQOL-SRPB, esta questão se amplia, e os dois temas tendem a se complementarem. A metodologia de desenvolvimento do módulo WHOQOL-SRPB seguiu a dos outros projetos do Grupo WHOQOL, inclusive com a participação do centro brasileiro.

O capítulo 9, "Desenvolvimento do instrumento WHOQOL-OLD", é assinado pelo professor Fleck, o psiquiatra Eduardo Chachamovich, a psicóloga Clarissa Marceli Trentini, a psicóloga Silke Schmidt e Mick Power, professor de Psicologia Clínica e consultor honorário de Psicologia Clínica do Royal Edinburgh Hospital. Este novo instrumento tem como objetivo "oferecer um conjunto de itens adicionais para a avaliação da QV em idosos, gerados a partir de uma metodologia transcultural que permita comparações fidedignas das medições em diferentes contextos culturais".

O décimo capítulo já faz parte da segunda metade do livro. O professor Fleck e a psiquiatra Ana Flávia Barros da Silva Lima apresentam uma comparação do uso do WHOQOL-bref e do SF-36 (Medical Outcomes Study Short Form 36) em dependentes do álcool.

No capítulo seguinte, é discutida a QV em pacientes deprimidos. Os autores são o professor Fleck, o psiquiatra e mestre Marcelo Berlim, a acadêmica de Medicina da UFGRS Juliana Brenner, o residente de Psiquiatria Marco Antonio Knob Caldieraro e a médica Joana Silveira Pargendler. A depressão é uma doença séria, considerada um problema de saúde pública, o qual necessita de extensos estudos, almejando uma melhor QV de seus portadores.

No capítulo 12, é discutida a QV em pacientes com ansiedade pela doutora em Bioquímica Gisele Gus Manfro e pela enfermeira doutora Elizeth Heldt. Da mesma forma que a depressão, os transtornos ansiosos merecem cada vez mais estudos longitudinais.

A QV dos pacientes bipolares é discutida no capítulo 13, pelo psiquiatra Fernando Kratz Gazalle e pelo psiquiatra doutor Flávio Kapczinski. Embora com muitas pesquisas básicas e experimentais, os pacientes bipolares necessitam maior assistência de melhoria da sua QV.

No próximo capítulo, o professor Fleck e a professora doutora Luciane Carniel Wagner discutem a avaliação da QV na esquizofrenia.

O psiquiatra e mestre Rogério Zimpel, juntamente com o professor Fleck, apresenta no $15^{\circ}$ capítulo um estudo brasileiro sobre a QV em pacientes com HIV/ AIDS.

No capítulo 16, o professor Fleck e o psiquiatra Jacques José Zimmermann apresentam uma discussão sobre a "Recordação dos cuidados parentais e QV na idade adulta".

Os mesmos autores do capítulo 8 (com exceção de Joana Pargendler), juntamente com a psicóloga doutora Denise Bandeira, discutem "Espiritualidade, religiosidade e QV", inclusive com pesquisas brasileiras, no capítulo 17.

O $18^{\circ}$ capítulo, "QV em cardiopatia isquêmica", é assinado pelo professor Fleck, a psiquiatra doutora Luciane Nascimento Cruz e a professora cardiologista Carisi Anne Polanczyk. integração da psiquiatria com outras especialidades tem proporcionado grandes avanços nos estudos de QV.

O capítulo 19 tem os mesmos autores do capítulo 18 e discorre sobre a QV em insuficiência renal crônica.

No último capítulo, é discutida a QV em idosos, por Fleck, a psicóloga professora Clarissa Trentini e o psiquiatra mestre Eduardo Chachamovich.

Este tomo repercutirá, positivamente, em todos os centros de pesquisa de QV de língua portuguesa, tornando-se referência obrigatória para todos os iniciantes e experientes estudiosos desta área. 